\title{
Discount deals becoming a medical rage
}

$\mathrm{D}$ eals for half-off Botox treatments, hair transplants or liposuction haven't traditionally shown up in bargain bins. Nor have advertisements asserting that "detox foot pads" are "the secret to soothing your battered body" exactly been a medical norm. Well, perhaps, not since the days when medicine men flogged their wares from the back of buggies.

But in the brave new worlds of Internet advertising and collective Internet buying, in which progressive discounts of $50 \%$ to $60 \%$ to even $70 \%$ or more are offered if a pre-set number of buyers sign on to a 'deal', it seems that medicine is rapidly returning to days of yore.

An increasing number of daily discounts for medical services and products can be found on websites like Groupon, LivingSocial and SwarmJam in the United States and Canada as providers and vendors explore new avenues of attracting customers.

For consumers, the appeal is simply the lower prices, says Dr. Anthony Youn, a Michigan-based plastic surgeon and member of the American Society of Plastic Surgeons, whose website offers "a full range of surgical and nonsurgical treatments to enhance your appearance."

But there's a definite upside for providers as well, particularly those looking to establish their businesses, Youn says. While established surgeons aren't likely to offer daily deals, and Youn himself doesn't offer such online deals, he says newer clinics or physicians are often looking for fresh ways to advertise their services. "It's an easy way to get patients in the door - it's an almost guaranteed way."

The risk, of course, is that uninformed consumers may be exposed to unnecessary risk. For example, there's a difference between a chemical peel and liposuction, Youn says, warning that the latter is a serious procedure, with real potential risks. In extreme cases, he adds, Botox can be life threatening since there is the risk of an aller-

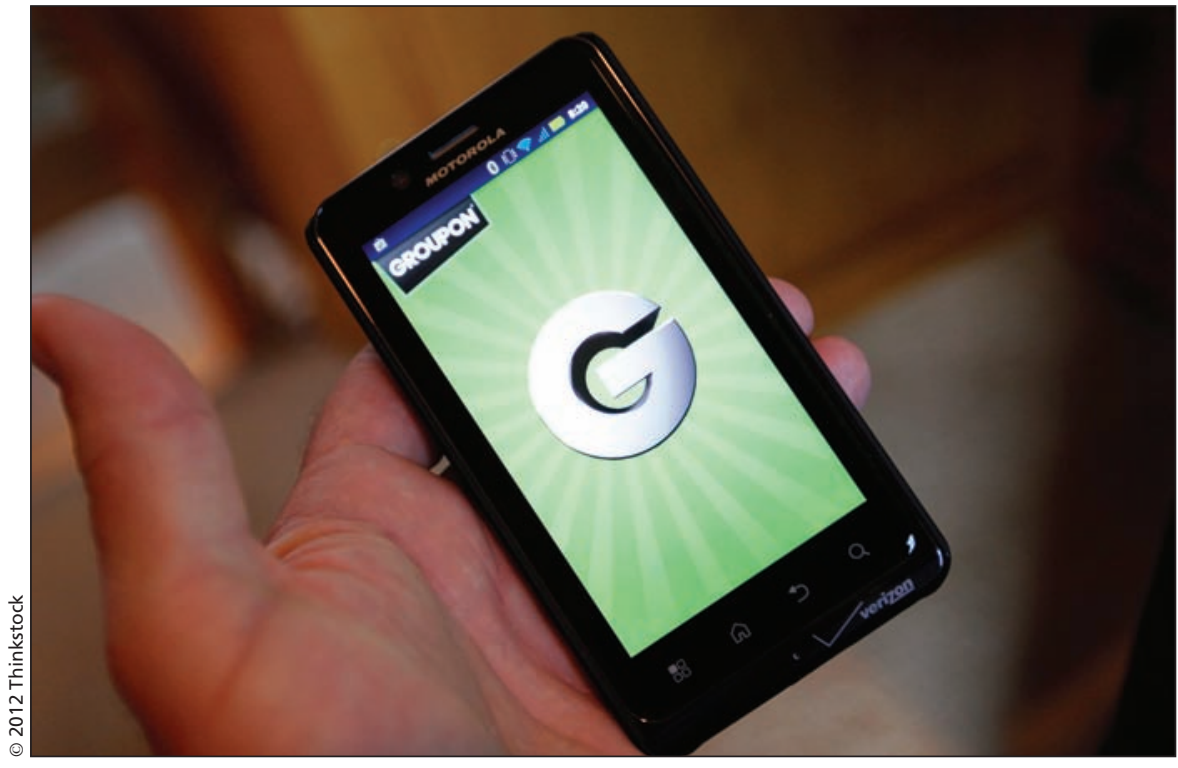

Websites such as Groupon, LivingSocial and SwarmJam in the United States and Canada are increasingly offering medical services and products as providers and vendors explore new avenues of attracting customers.

gic reaction or complications with a pre-existing condition.

It's therefore important that consumers obtain their deals from credible providers, if they're in fact interested in purchasing such services, Youn argues.

Youn also suggests that consumers should examine whether a website provides adequate safety warnings and refunds.

A recent Groupon offer for Botox treatment, for example, did include a disclaimer which stated that "Botox may cause serious side effects that can be life threatening, including problems swallowing, speaking, or breathing." It also included a link to a list of safety considerations associated with the use of Botox.

Yet even such warnings aren't adequate, Youn says, noting that cigarette labels have warnings which are systematically ignored by consumers. It's important that providers have ethical standards, Youn says, noting that he turns away about one in five patients who seek surgery because their expectations are unrealistic or it isn't medically indicated.
"We want to avoid any type of coercion where the patient feels because they have this $\$ 500$ that they've already spent, they have to use it on Botox, even though it may not (be) in their best interests," he says.

But Groupon's policy is to always offer customers a refund for the amount paid. A recent Groupon deal, for example, put that promise directly in the offer, stating: "Consultation required; non-candidates will be refunded." Youn says coupons that offer patients such refunds are more credible than those that don't, because they give patients an "out. ... To use coupons is reasonable, as long as the physician always has the patients' best interests in mind, because it is a very competitive market."

Yet a refund isn't in and of itself any manner of guarantee, as the offer itself may be unreasonable, as was the case in the United Kingdom recently when the Advertising Standards Authority banned a promotional email from Groupon offering discount breast augmentation or rhinoplasty, because it "pressured" consumers to make a decision about cosmetic surgery within 24 
hours (www.asa.org.uk/ASA-action /Adjudications/2011/11/MyCityDeal-Ltd /SHP_ADJ_161777.aspx).

Given the health risks and the potential severity of the consequences, some critics believe that physicians and other medical service or equipment providers shouldn't be allowed to tap into collective Internet buying or other forms of Internet advertising.

Online bargains are simply a new way to put pressure on consumers, argues Dr. Leonore Tiefer, a clinical associate professor of psychiatry at the New York University School of Medicine in New York City. "It kind of indulges in the temptation side of consumerism, which I think is generally not good for people, to encourage their impulse purchasing," she says. "You end up getting more, doing more, spending more, using more than you intended to in a kind of calmer, more rational, more planful moment."

There's a need for improved consumer education about medical advertising, so that they can approach pitches with a healthy level of skepticism, Tiefer argues. "It's gone beyond information, many decades beyond information - now it's about seduction. And I'm concerned about the creation of insecurity and dissatisfaction and competitiveness about the body in the way that we have competitiveness about every other product."

Advertising is permissible within the cosmetic surgery industry, although there are some federal, provincial and territorial regulations. Health Canada states on its website that health product advertisements must be "reviewed and precleared" by self-regulatory industry agencies such as the Pharmaceutical Advertising Advisory Board or Advertising Standards Canada (www.hc-sc.gc.ca /dhp-mps/advert-publicit/index-eng.php).

Health Canada also states that "Section C.01.044 of the Food and Drug Regulations restricts the advertising of a prescription drug to consumers to the mention of the name, price or quantity" (www.hc-sc.gc.ca/dhp-mps/advert-pub licit/pol/notice-avis_reminder-rappel-eng .php). The department adds that it has reviewed complaints on that point and "is in agreement that when advertising campaigns allow consumers to identify the therapeutic indication of a prescription drug," the limitations of the regulations have been exceeded. In short, no reference can be made to a drug's therapeutic use or benefits.

Many provinces also have laws or regulations that restrict how physicians advertise their practice. In Ontario, for example, a provision of the Medicine Act states that information communicated to the public that could be relevant to their choice of a physician must not "contain any reference to a specific drug, appliance or equipment" (www .e-laws.gov.on.ca/html/regs/english /elaws_regs_940114_e.htm).
But the restrictions appear to be misunderstood by some practitioners. Health Canada's website notes that the department has received complaints about physicians advertising prescription drugs to consumers on their websites. The department "suspects physicians may not be aware of the federal advertising prohibitions or their application to physician advertising" (www .hc-sc.gc.ca/dhp-mps/advert-publicit/pol /web-qa-qr-eng.php\#note1).

Advertising is fairly common, says Dr. Howard Clarke, head of public relations for the Canadian Society of Plastic Surgeons. Even some high-end clinics try to sell their treatments on their websites, and online coupons are just another form of advertising, he says.

Clarke notes that there is some selfregulation among plastic surgeons. For example, members of both the US and Canadian Societies of Plastic Surgeons are precluded from giving away surgery as a prize in something like a raffle or contest.

The online pitches do not compromise ethical principles as there is always consultation with a surgeon before surgery is performed and there is always the option of a refund, Clarke says. "It's still odd that you're paying up front. But I don't think odd makes it wrong, it just makes it odd." — Julia Sisler, Ottawa, Ont.

CMAJ 2012. DOI:10.1503/cmaj.109-4089 